\title{
The Impact Of Information Quality And Ergonomics On Service Quality In The Use Of Automatic Teller Machines
}

\author{
Jeremy C. Elias ${ }^{1, *}$, and Rene D. Estember ${ }^{1}$, \\ ${ }^{1}$ School of Industrial Engineering and Service Engineering Management, Mapúa University 658 Muralla St., Intramuros, Manila 1002, \\ Philippines
}

\begin{abstract}
The introduction of automatic teller machines (henceforth ATMs) brought dramatic changes in the way people do banking. ATMs have become a daily necessity and they are widely used for their convenience and accessibility. However, there have been several major challenges and issues faced in delivering quality service in ATM banking. Since the use of ATMs involves an exchange of information between a machine and a customer, this study investigated the impact of information quality (i.e., quality of information the machine provides) and ergonomics (i.e., design quality of the machine) to the service quality of ATMs. To this end, the study geared towards providing an improvement framework for the ATM design to improve service quality. A random survey among ATM users in Metro Manila was conducted to gather data with regard to their usage and perceived service quality of ATMs. Through statistical analyses, it was found that ATM usage varied according to age, education and socio-economic status of customers. ATM users were typically young, more literate and have higher economic status. More importantly, it was found that components of information and ergonomic qualities had fair influence to service quality, with just a few components having significant impact.
\end{abstract}

\section{Introduction}

Superiority in quality has developed as an essential for administrative sustainability in this competitive world [1]. On top of that, the changing customers' perception of quality poses unique challenges. Administration of client coordination and service quality is the utmost efficient ways of making trust in the competitive organization industries such as banks [2].

The expansion of information and telecommunication technologies has allowed establishments to deliver excellent amenities to fulfill customers requirements [3]. Banks are amassed their services options based on technology to meet the demand of this competitive world and ATM facilities are one of such services. ATM is an automatic telecommunication device that provides instant financial transaction facility for customers without depending on the banking personal for manual transaction [4].

Banks keep developing the range of the ATM system to meet the needs of consumers with lower transaction cost for both bank and consumers. However, ATMs are public technology devices [5]. This means that people who may use ATMs vary from age, gender, literacy, behavior, social and economic status and other factors, thus raising major challenges and issues in delivering quality service in ATM banking.

Issues on the use of ATMs have been attended from a number of perceptions such as age [6], control modality including voice [7], language [8], attitudes to innovativeness and computers [9], interface design [10] literacy [9], and attributes of ATM users [11,12].

Most of the previous studies about ATMs were able to identify prospects and problems concerning the use of ATMs. Also, they have provided suggestions and recommendations to address these concerns such as design to accommodate the older population, providing training and additional different alternative ATM interface. However, none of these studies have provided an in-depth analysis on the service quality of ATMs. Service quality is the evaluation of the service level delivered to the customer based on the customers expectation [13]. It is the customer's verdict about an unit's overall quality or preeminence. This means that if the client recognizes facility at a certain level but estimated something different, then the consumer will be discontented. In manufacturing, consumers judge the quality by evaluating the product manufactured. In contrast, service customers judge service quality by experiencing the service delivery processes as well as the outcome. In other words, customer satisfaction is the outcome of service quality.

On the other hand, a study made by Najjar [14] investigated the impact of information quality and ergonomics on service quality in selected banks in Nebraska, United States. His study involved the traditional over-the-counter banking setup. A model postulating that process quality predicts product/service quality was proposed. Bank employees were asked to assess through a questionnaire how information quality

*Corresponding author: jeremyelias22@gmail.com 
and ergonomics (workstation, overall comfort, and environment) affect how they deliver the service. However, in the case of ATMs, in which service is delivered only by a machine, is the service quality predicted by the quality of information provided by the machine and the ergonomics of the machine itself?. With this, the researcher wanted to extend Najjar's [14] principle to the concept of ATMs. Nowadays, organizations increasingly rely on their information systems to integrate and support their business processes [15]. These information systems and the quality of the data they contain affect customer's perceptions of the quality of purchased products and services [16]. With that being said, since the ATM interface requires an exchange of information between the user and the machine, this study determined the impact of information quality (i.e., the quality of information the machine provides) and ergonomics (i.e., the machine design) in delivering quality service in the use of ATMs. In improving service quality, this study geared towards providing an improvement framework for the ATM design.

\section{Methodology}

In the course of the study, the researcher followed the methodological framework shown in Figure 1.

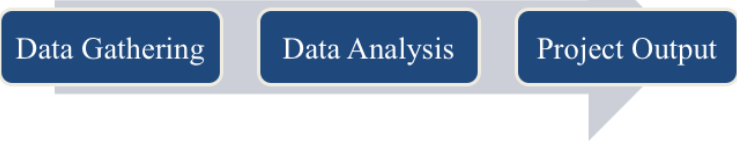

Fig. 1. Research Framework

\subsection{Data Gathering}

The sample for this study was composed of 250 individuals coming from Metro Manila who were actively using ATM services. ATM users from the three largest banks as to total assets reported by the Bangko Sentral ng Pilipinas (BSP) as of the end of December 2013 were selected. Coincidentally, these were also the banks with the largest number of ATM units as of the 2nd quarter of 2011 .

A two-part random survey was conducted using questionnaires. The first part was the preliminary survey. The purpose of the preliminary survey was to gather information about customers' ATM usage and to identify customers' needs and demands as well. The second part of the survey asked the respondents to rate their respective banks in terms of their perceived quality of its service, information, and ergonomic design. The survey used a 10 point rating scale with 1 being the lowest and 10 being the highest.

Firstly, the survey helped draw a profile of customers' ATM usage based on their age, gender, education, and socio-economic status. Secondly, this helped determine the problems experienced by customers with ATMs. And third, it helped determine what customers demand for quality service, information and ergonomics and how they perceive the quality of service that ATMs of their respective banks provide.

\subsection{Data Analysis}

The data gathered from the survey was statistically analyzed. Descriptive statistics was used to draw a basic profile of ATM usage in Metro Manila and the problems customers experienced with its use. General Linear Model and T-test were used to find out significant variations in customer's ATM usage based on their age, gender, education, and socio-economic status. General Linear Model was also used to find out significant difference in the customer's perceived service, information, and ergonomic qualities of the ATMs of their respective banks.

The impact of information quality and ergonomics on service quality was tested using Simple Linear Regression. Each independent variable (i.e., information and ergonomic components) was used to predict the value or its impact to the dependent variable (i.e., service quality components).

Tools such as Pareto chart and Fishbone diagrams were used for cause and effect analysis. The Pareto chart was used to determine which of the many problems were significant and needed to be prioritized. The Fishbone diagram was then used to determine the causes of these problems, as well as what causes the causes or the socalled root cause. The findings in the cause and effect analysis served as minimum basic guidelines in creating an improvement framework for ATM design.

The primary output of this study is an improvement framework for the ATM design using House of Quality (HOQ). It was used to highlight the voice of the customers (i.e., customer wants). It is a implement to explain what the client desires into products or services that meet the consumer requirements in terms of engineering design standards by way of generating a relationship matrix. Basically, HOQ is comprises of six main mechanisms. They are technical requirements, customer requirements, an interrelationship matrix, competitor evaluation, a technical priorities and technical correlation matrix, benchmarks and targets section. Figure 2 shows project design framework.

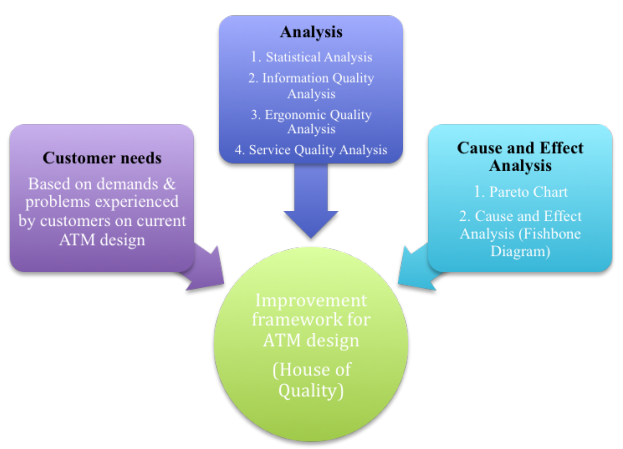

Fig. 2. Project Design Framework 


\section{Results and Discussion}

Generally, the survey showed that ATM users were typically young, being more educated and having higher economic status. $65 \%$ of the respondents fell under the age of 39 years old and below. Around 97\% have finished at least secondary education and $72 \%$ were earning from average to high income. Around 45 percent of the users have been using ATM for only 5 years or less as shown in Figure 3. In addition, the survey result showed that almost 70 percent owned one (1) ATM card only. As for the atm usage, it was found that around 46 percent were using ATMs twice $(2 \mathrm{x})$ within a week as shown in Figure 4. Typical ATM usage time among respondents ranged from 30 seconds to 1 minute. Convenience was the topmost reason for using ATMs and cash withdrawal had $100 \%$ utilization.

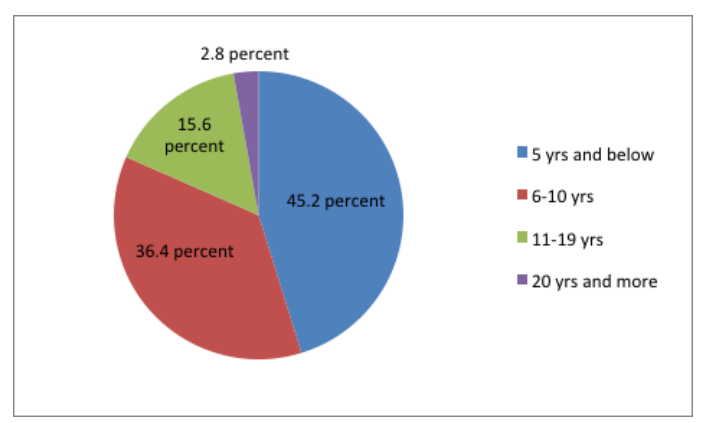

Fig. 3. Length of ATM Use

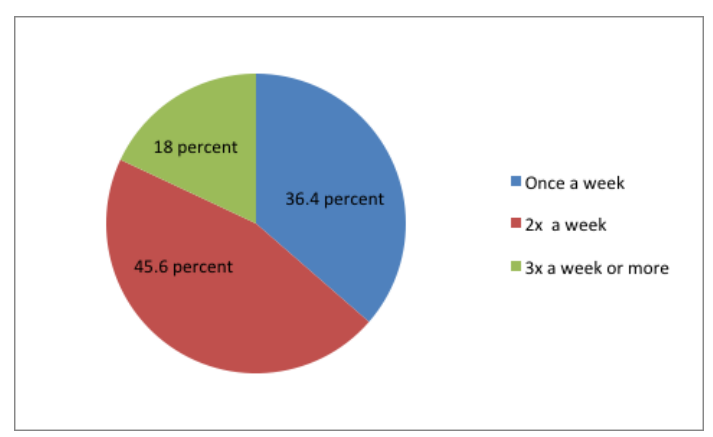

Fig. 4. Frequency of ATM Use

Respondents were asked for their reasons for using an ATM. From Figure 5, at approximately 97 percent, customers found convenience as their topmost reason for using an ATM. Easier accessibility of ATMs as compared to branch offices was also a major reason why 68 percent of the respondents use ATM. 47 percent of the respondents also identified 24-hour service as a major reason for using an ATM.

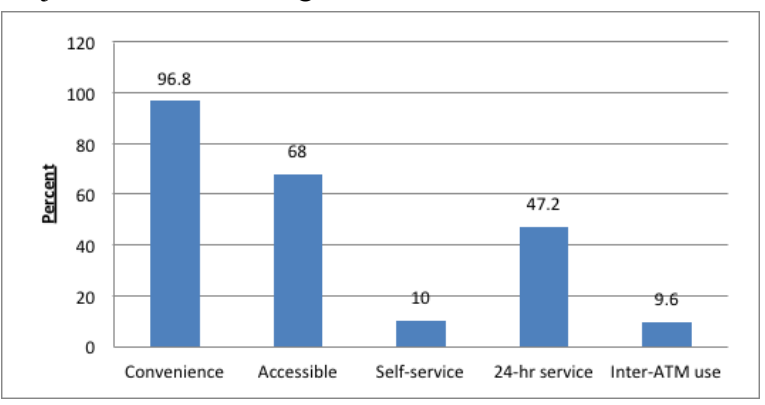

Fig. 5. Reasons for Using ATM
Table 1. Problem Experienced by Customers

\begin{tabular}{|l|l|l|}
\hline Problem & frequency & Percentage \\
\hline ATM is offline or out of service & 234 & 93.6 \\
\hline Long queue & 232 & 92.8 \\
\hline ATM not printing receipt & 154 & 61.6 \\
\hline ATM running out of money & 115 & 46 \\
\hline $\begin{array}{l}\text { Difficulty seeing the keypad (due to } \\
\text { cover) }\end{array}$ & 82 & 32.8 \\
\hline Security problems & 71 & 28.4 \\
\hline $\begin{array}{l}\text { ATM not dispensing cash, but } \\
\text { debited on account }\end{array}$ & 40 & 16 \\
\hline Poor visibility of screen & 39 & 15.6 \\
\hline ATM working too slowly & 38 & 15.2 \\
\hline Inserting card incorrectly & 34 & 13.6 \\
\hline $\begin{array}{l}\text { ATM not releasing card card } \\
\text { captured) }\end{array}$ & 30 & 12 \\
\hline $\begin{array}{l}\text { Don't know w/c keys and buttons to } \\
\text { press }\end{array}$ & 23 & 9.2 \\
\hline Forgetting the PIN & 22 & 8.8 \\
\hline Insufficient lighting at ATM facility & 20 & 8 \\
\hline Not knowing if ATM is operating & 19 & 7.6 \\
\hline Inconvenient location & 15 & 6 \\
\hline ATM charge high fees & 13 & 5.2 \\
\hline Unclear instructions & 11 & 4.4 \\
\hline $\begin{array}{l}\text { Difficulty reaching the slot (height } \\
\text { of the machine) }\end{array}$ & 2 & 0.8 \\
\hline
\end{tabular}

Using, General Linear Model and T-test, ATM usage was found to be significantly different with customers' age, education, civil status, income and occupation with most of the P-values equal to $<0.0001(\alpha=0.05)$. Basically, ATM usage pertains to the period of ATM use (i.e., how long the customer has been using ATM banking), card ownership (i.e., how many cards the customer own), frequency of ATM use (i.e., how often the customer use an ATM within a week), and ATM usage time (i.e., how much time it takes the customer in using ATM). On the other hand, ATM usage was found to be the same with both men and women except that men were faster in using ATMs.

In addition, comparison was done between local banks in Philippines namely BDO, Metrobank and BPI bank. Overall, the three banks were likely the same with their service quality components except for communication. With that, the three banks were found to be significantly different in terms of communication alone with $\mathrm{P}$ value equals to less than 0.0001 . Descriptively, using the equivalent rating scale, the respondents were "extremely satisfied" with the quality of information their banks' Overall, the three banks were not significantly different in terms of ergonomic quality components. Overall service quality (SQ) rating was $8.199,8.531$ for information quality (IQ), and 7.810 for ergonomic quality (EQ).

Additionally, the banks were significantly different with the Communication component of service quality with P-value of $<0.0001$. This difference was mainly due to the language options incorporated in the Furthermore, the Simple Linear Regression test revealed that information and ergonomic quality components generally had fair impact or effect to service quality components, with only few components having significant impact. Consistency of information had 
significant impact to Competence of service quality with P-value of 0.0038. It was found out that for every 1 point increase in the Consistency rating there's approximately 0.15 increase in the Competence value of service quality. That is,

Competence $=6.67045+0.14719($ Consistency $)$

Moreover, the ergonomic components of Lighting and Keypad had significant impact to the Tangibles of service quality.

$$
\begin{aligned}
& \text { Tangibles }=11.75384-0.27566(\text { Lighting }) \\
& 0.25396(\text { Keypad })
\end{aligned}
$$

It means that for every 1 point increase in the rating for Lighting there's around 0.28 decrease in the value of Tangibles. Also, for every 1 point increase in the rating for the Keypad there's around 0.25 decrease in Tangibles. However, since the parameter estimate was 11.75384 which exceeds the highest score which is 10 , improvement in the ratings of both components would bring the Tangibles score in the acceptable range.

Furthermore, the House of Quality was utilized as a tool to provide an improvement framework for the ATM design in order to improve service quality. Table 2 shows the customer requirements which were derived from the survey and the technical requirements which were drawn from cause and effect analysis.

Table 2. Customer requirements and Technical Requirements

\begin{tabular}{|l|l|l|}
\hline \multicolumn{2}{|l|}{$\begin{array}{l}\text { Customer Requirements } \\
\text { (Whats) }\end{array}$} & Technical Requirements \\
\hline SQ & $\begin{array}{l}\text { Security of } \\
\text { service(Safety) }\end{array}$ & $\begin{array}{l}\text { Improve security } \\
\text { measures }\end{array}$ \\
\cline { 2 - 3 } & Accessibility of service & Convenient locations \\
\cline { 2 - 3 } & Reliability & ATM always online \\
\hline IQ & $\begin{array}{l}\text { Security } \\
\text { (Conficentiality of } \\
\text { information) }\end{array}$ & Security biometrics \\
\cline { 2 - 3 } & Accuracy & $\begin{array}{l}\text { Accurate transaction } \\
\text { account details }\end{array}$ \\
\cline { 2 - 3 } & $\begin{array}{l}\text { Accessibility of } \\
\text { information }\end{array}$ & $\begin{array}{l}\text { Avaiability of needed } \\
\text { information }\end{array}$ \\
\cline { 2 - 3 } & Understandability & Language options \\
\cline { 2 - 3 } & Completeness & Issuance of receipt \\
\hline EQ & Keypad & Improve keypad cover \\
\cline { 2 - 3 } & $\begin{array}{l}\text { Keys \& buttons on the } \\
\text { screen }\end{array}$ & $\begin{array}{l}\text { Mapping of keys \& } \\
\text { buttons }\end{array}$ \\
\cline { 2 - 3 } & Screen & $\begin{array}{l}\text { Change screen glass } \\
\text { material }\end{array}$ \\
\hline
\end{tabular}

In addition as illustrated in Figure 6, based on the framework, the ATM design improvement framework suggested that:

The technical requirements should be prioritized in the following order:

1. Improve security measures (including security biometrics)

2. Accessible and convenient locations

3. Keys and buttons on the screen
4. Improve keypad cover (trade-off between security biometrics)

5. ATM always online

6. Issuance of receipt

7. Availability of needed information

8. Accurate transaction/account details

9. Reduce glare on the screen

10. Incorporate language options

The achievement of all the technical requirements will have the most impact to the following customer requirements:

1. Security of service (safety)

2. Accuracy of information

3. Security of information (confidentiality)

4. Accessibility of service

5. Reliability of service

6. Keys and buttons on the screen

7. Accessibility of information

8. Screen

9. Understandability of information

10. Keypad

11. Completeness of information

Five of the targets are found only in the improved ATM design such as:

1. Panic button

2. Monitoring system of ATM traffic

3. Fingerprint or eye recognition technology

4. Transaction history option

5. Non-glare glass

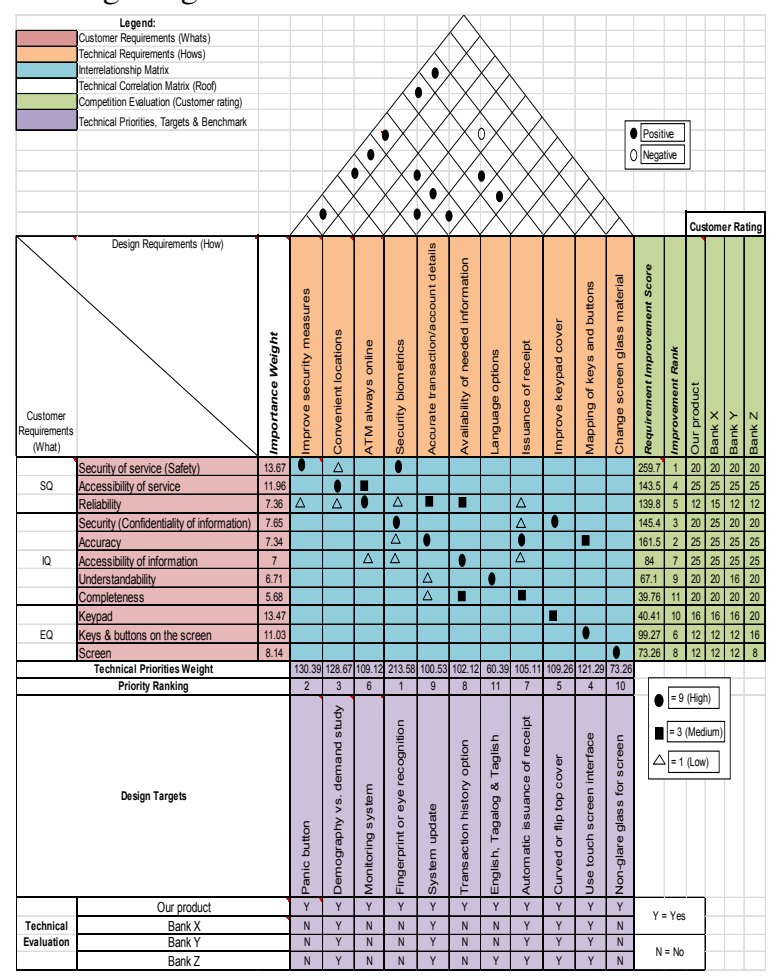

Fig. 6. Improvement Framework for ATM Design

\section{Conclusion}

In this study, the researcher found out that ATM users were typically young, being more educated, and having higher economic status. Common problems with the use 
of ATM were also identified in this study. ATMs being out of service and customers having to wait in long queues were the most commonly experienced problems. Additionally, ATMs not printing receipt and running out of money were also frequently experienced. Categorically, system-related problems were likely to occur the most. This means that most ATM related problems had the ATM's system itself as its source. Furthermore, ATM users were significantly different with their ATM usage in terms of their age, education, income, civil status, and occupation. Older, educated, married, employed and higher earning groups tend to have higher or greater ATM usage as compared to their counterparts. Moreover, as for this study, information quality (IQ) and ergonomic quality (EQ) components in general do not have significant impact or effect to service quality (SQ) components. Information, ergonomic, and service qualities are independent entities which people perceived separately. However, there were certain components of information and ergonomic qualities which were found to impact certain components of service quality. Particularly, consistency of information was found to impact competence of service, and the lighting and keypad were found to significantly affect the quality of design (tangibles) of ATMs. More importantly, this study was able to provide an improvement framework for the ATM design that could serve as a basis for future researches and projects in designing an automatic teller machine.

\section{References}

1. Lewis, B., Orledge, J., \& Mitchell, V. (1994). Service quality: students' assessments of banks and societies. International Journal of Bank Marketing 2(4), 3-12.

2. Athanassopoulos, A. (2000). Customer satisfaction cues to support market segmentation and explain switching behavior. Journal of Business Research 47(3), 191-207.

3. Surjadjaja, H., Ghosh, S., \& Anthony, J. (2003). Determining and assessing the determinants of eservice operations. Managing Serving Quality 13(1), 39-53.

4. Dhungel, A., Acharya, B., \& Dhungel, K. (2002). Perception of bank customers about automated teller machine (ATM). Banking Journal 2(2), 23-38.

5. Baber, C., Stanton, N., \& Johnson, G. (1998). Editorial. From public technology to ubiquitous computing: Implications for ergonomics. Ergonomics 41, 921-926.

6. Chan, C., Wong, A., Lee, T., \& Chi, I. (2009). Modified automatic teller machine prototype for older adults: A case study of participative approach to inclusive design. Applied Ergonomics 40, 151160 .

7. Hone, K., Graham, R., Maquire, M., Baber, C., \& Johnson, G. (1998). Speech technology for automatic teller machines: An investigation of user attitude and performance. Ergonomics 41, 962-981.
8. Dix, A., Finlayson, J., Abowd, G., \& Beale, R. (1998). Human-Computer Interaction, second edition. London: Prentice-Hall.

9. Thatcher, A., Shaikh, F., \& Zimmermann, C. (2005). Attitudes of semi-literate and literate bank account holders to the use of automatic teller machines (ATMs). International Journal of Industrial Ergonomics 35(2), 115-130.

10. Mahmood, T., Shaikh, G.M. (2013). Adaptive automated teller machines. Expert Systems with Application 40, 1152-1169.

11. Khawaja, K., \& Manarvi, I. (2009). Evaluating customer perceptions towards atm services in financial institutions; a case study of pakistani banks. International conference on computers and industrial engineering (pp. 1440-1445). CIE.

12. M. B. Calayag, D. M. M. Regala, C. J. R. Rivera, and D. M. N. Tancio, "A Comparative Study of Different Automated Teller Machine and Its Effectiveness Based on Customer's Satisfaction," J. Ind. Eng. Manag. Sci., vol. 2017, no. 1, pp. 49-102, 2017.

13. Lewis, R., \& Booms, B. (1983). The marketing aspects of service quality. In L. Berry, G. Shostack, \& G. (. Upah, Emerging Perspectives on Services Marketing (pp. 99-107). Chicago, IL: American Marketing.

14. Najjar, L. (2002). The impact of information quality and ergonomics on service quality in the banking industry. Michigan: ProQuest Information and Learning.

15. Wang, R., \& Kon, H. (1993). Toward total data quality management. In R. (. Wang, Information technology in action: Trends and perspectives ( $\mathrm{pp}$. 179-197). Englewood Cliffs, NJ: Prentice Hall.

16. Wang, R., \& Strong, D. (1996). Beyond Accuracy: What data quality means to data consumers. Journal of Information Management Systems 12(4), 5-34. 